\title{
El Modernismo catalán frente al hispánico
}

\author{
Montserrat Escartín Gual
}

Para acercarse al fin de siglo en la literatura catalana habría que partir de sus tópicos y redefinirlos, empezando por el de su nombre. Dado que Modernismo no significa lo mismo para el ámbito cultural catalán, español e hispanoamericano, es imprescindible aludir a la clásica matización que Lluís Marfany hace del término para puntualizar su significado, ${ }^{1}$ viéndolo como una actitud, un período o un estilo. La actitud de un sector de la sociedad catalana que creyó necesaria su reforma cultural, junto al renacimiento de su lengua como vehículo de cultura, y cuya pose de modernidad derivó hacia una ideología: el catalanismo. ${ }^{2}$ Modernisme define también el período histórico que va de 1890 a 1910, cuando predomina la actitud modernista y en el que nace un movimiento literario que ataca tanto la España de la Restauración como la Renaixença catalana. Formado por un grupo de escritores que asimila múltiples tendencias europeas y une esfuerzos con el objetivo de hacer triunfar sus ideas desde 1893 hasta la aparición del Noucentisme en 1906. En tercer lugar, el término denomina la traducción de la modernidad a una tendencia de las artes decorativas, cuya expresión en arquitectura, muebles u orfebrería, es bien estudiada por Alexandre Cirici PeIlicer. ${ }^{3}$ Algunos críticos han reservado para dicha estética la expresión Art nouveau, dejando la voz Modernisme para la realidad histórica que va más allá de un estilo, porque Modernisme supone la simultaneidad de varios. ${ }^{4}$

Mientras el Modernisme se manifiesta como ideología en su etapa inicial, el término es claro; su ambigüedad surge cuando se aísla o politiza en una segunda etapa, entonces las actitudes de búsqueda de la modernidad son asumidas desde la creación artística. Pero, aunque entre los ideólogos del 1890 y los creadores de 1905 haya cambios, la actitud de fondo y las tensiones entre autor y sociedad son las mismas. Sólo en este sentido se puede hablar de Modernismo-período. ${ }^{5}$ En síntesis, Modernisme es un término que empezó denominando

\footnotetext{
L1. Marfany [1975:35 y 1982:32].

Ll. Marfany [1978] y V. Cacho Viu [1984].

Por A. Cirici Pellicer [1951].

4 J. Ràfols [1949].

5 J. Castellanos [1988:188].
} 
un programa de regeneración social de ideología progresista y que acabó siendo la etiqueta de unas determinadas formas estéticas, bien ajenas al radicalismo inicial, en manos de grupos conservadores que también se sentían «modernos» a pesar de su ideología.

Podríamos intentar definir al Modernisme como el resultado de la coincidencia entre una actitud y un período que, en algún instante, se organiza como movimiento, lo cual nos lleva a otro punto de interés para los estudiosos: el esfuerzo por definirlo. La opinión más aceptada por la crítica ${ }^{6}$ es ver en el Modernisme un proceso de transformación de una cultura regionalista y una literatura anclada en la Renaixença hacia otra más moderna de tipo nacional, que durará dos décadas y será coronada por el Noucentisme; y la más refutada, la que limita dicho movimiento a una estética - el Simbolismo de los años 90 o el Decadentismo-. Sin duda porque el Modernisme integra, además de un movimiento o una actitud socio-cultural, un conjunto de principios estéticos traducibles en diferentes corrientes teóricas (tan antitéticas como el espontaneismo de Joan Maragall, el simbolismo de Santiago Rusiñol, el decorativismo de Alexandre de Riquer, el teatro libre de Adrià Gual o la filosofía de Friedrich Nietzsche, introducido en Cataluña y España por Maragall). ${ }^{7}$ Modernisme es sinónimo de actitud de vanguardia que puede aglutinar tendencias tan diversas como la anarquizante y aristocrática, la esteticista o simbolista así como el compromiso social o lo patriótico. Que en su ideario no haya unos principios estéticos explícitos no impide que posea una determinada concepción filosófica en torno al lugar y sentido que ocupa el artista en el mundo. Las dos corrientes teóricas que predominan en el Modernisme - espontaneidad y arbitrariedad-, conviven desde 1898 interrelacionándose; aunque, en un principio, destaque el espontaneismo y, desde 1902, la arbitrariedad expresada en formas simbolistas, parnasianas o prerrafaelitas, que el ideario estético del Noucentisme seguirá sosteniendo. ${ }^{8}$

Otro punto conflictivo en la valoración del Modernisme es el de su cronología. Si en el ámbito español, se elige la publicación de $A z u l$ (1888), de Rubén Darío, o la llegada a España de éste en 1892 para hablar de su inicio y,1915 para su fin; en Cataluña hay que remontarse a 1881 , cuando aparece L'Avenç, revista donde se usó el término modernista por vez primera o 1888, año de la Exposición Internacional de Barcelona, para marcar su comienzo; hasta 1906, cuando irrumpe el Noucentisme, aunque se cite como fecha de cierre 1911 por ser la de la muerte del poeta Joan Maragall y del pintor Isidre Nonell. Dentro de la trayectoria vital del Modernisme, se acepta la existencia de dos períodos —de 1892 a 1900 y de 1900 a 1911 - desde la clasificación de Joaquim Molas. ${ }^{9}$ El primero, se expresaría a través de cuatro revistas: dos de tipo literario, $L^{\prime}$ Avenç y Catalònia, junto a otras dedicadas a las artes plásticas, Pèl i Ploma o Quatre gats, nombre nacido de la cervecería donde la bohemia barcelonesa se reunía. El regeneracionismo inicial de $L^{\prime}$ Avenç ${ }^{10}$ se concretó en dos consignas: una de-

\footnotetext{
6 Ll. Marfany [1982] y E. Valentí [ 1973].

7 E. Valentí [1973:123].

8 J. Castellanos [1988:180] y J.Vallcorba [1994].

${ }^{9}$ J. Molas [1986:100].

${ }^{10}$ R. Pla [1975].
} 
fensora de la lengua catalana y su reforma, en pro de una mayor simplicidad expresiva, y otra, de la intelectualidad como agente de regeneración social a partir del modelo cultural europeo. En septiembre de 1892, la actitud política de $L ' A$ venç, ligada al federalismo, se radicaliza tras el éxito del artículo de Jaume Brossa, «Viure del passat», que puede considerarse un manifiesto oficioso del movimiento, por su talante programático, que marcará el inicio del Modernisme. En el segundo período - de 1900 a 1911 — culmina el movimiento en Cataluña y se produce, a la vez, su superación por el Noucentisme desde 1906. Lo primero es observable en Joventut (1900-1906), última gran revista del Modernisme que lo resume en tres rasgos definidores: su catalanismo, sosteniendo una política nacionalista en la base de su actividad cultural; su ruralismo, al revitalizar dicha temática que culminará en la narrativa; y su vitalismo, por cuanto defendía una individualidad aristocratizante o el mesianismo del artista frente a la sociedad burguesa. Joventut es palestra donde se intenta justificar científicamente el nacionalismo. Así, el período que va del 1898 a 1911 se caracteriza por la disolución del Modernisme dentro de la más pura catalanidad.

Vista la cronología, otro punto básico al estudiar el fenómeno del Modernismo catalán es su heterogeneidad en tanto que funde tendencias positivistas y racionales con las más antirracionalistas o idealistas. Si en España hablamos primero de una estética, que se suma después a una toma de conciencia ideológica - el 98-; en Cataluña, el Modernismo lo integra todo y en un orden inverso: una tendencia más ideológica, en la línea del regeneracionismo español, representada por el poeta y crítico Joan Maragall (1860-1911); y otra, más esteticista, de la mano del pintor y dramaturgo Santiago Rusiñol (1861-1931). " En la primera, Maragall es el crítico más clarividente del movimiento y figura óptima para valorar el cultivo simultáneo de las dos líneas citadas, ${ }^{12}$ aunque más cercano al pensar del 98 castellano que al Modernismo propiamente.

Los mejores exponentes del programa regeneracionista catalán serían dos artículos de Jaume Brossa: «Viure del passat» - ya citado- y «La joventut catalana d'ara»; junto al de Andreu Cortada: «El nou autonomisme català». Tras el primer artículo de Brossa en 1892 (donde se criticaba la ridiculez del discurso españolista ante la celebración del descubrimiento de América, revisando la actitud semejante que el catalanismo de la Renaixença suponía respecto de su tradición), ${ }^{13}$ se intenta un programa común de éste y Rusiñol, para reconstruir la personalidad de Cataluña y modernizarla a través de su apertura a Europa. Su contenido era más que político, moral, educativo e intelectual; y, en él, la cultura fue el arma regeneradora cuyo fin era lograr una Cataluña culta, artística e intelectualmente superior. Artistas y escritores asumieron un papel de liderazgo social que antes no habían tenido bajo el ejemplo de Herik Ibsen, del que hicieron una lectura muy particular, destacando su individualismo. El plan de regeneración cultural debía comenzar por la mejora del individuo y culminar en la de la situación política, resultado de la transformación intelectual de la sociedad.

1 Estudiadas por J. Brossa [1969] y E. Raillard [1988:105] o E. Trenc [1988:143], respectivamente.

12 Ll. Marfany [1975]

1.3 J. Castellanos [1988]. 
Aunque el descontento ambiental era similar en toda España, su expresión fue distinta según cada contexto sociopolítico-cultural: la estancada meseta sin burguesía, afanes industriales, arcaica y prisionera de su casticismo, no pedía lo mismo que sus jóvenes escritores; situación muy distinta de la Cataluña burguesa que demandaba, como sus intelectuales, un nuevo producto artístico. ${ }^{14} \mathrm{La}$ sociedad catalana que forma la base del Modernisme tiene como componentes distintivos, por un lado, la masa de obreros y el tráfago de la ciudad industrial; $\mathrm{y}$, por otro, la propensión al snobismo de su burguesía, que se aficiona tanto a la arquitectura revival del pasado como a las audiciones wagnerianas en el Liceo, ${ }^{15}$ de cuya imitación surge la ópera catalana La fada, de Jaume Massó i Torrents. Esta decisiva intervención de la burguesía ha sido otro punto de interés para los críticos que han visto en la relación que se da entre el artista y la sociedad un factor distintivo del Modernismo catalán, el cual nace de la euforia económica y cultural de los sectores burgueses, aunque acabe integrando grupos populares que asumirán sus presupuestos. Cuando el movimiento se acerca a su fin, la burguesía no es ya la clase revolucionaria que lo originó y la protesta obrera y las bombas anarquistas evidencian que los modernistas son peligrosos (el enriquecimiento de la burguesía por la guerra de 1914 causa el enfrentamiento de clases que culminaría en la Semana Trágica). ${ }^{16}$ El signo más claro de la modernización de la burguesía catalana es que produce una generación de artistas-burgueses ( $\mathrm{Ru}$ siñol, en el arte; Maragall, en la literatura), con lo cual ser artista se convierte en una profesión socialmente aceptable, con el mismo valor que cualquier otra.

La relación conflictiva entre el artista y la sociedad ${ }^{17}$ sólo se da en Cataluña a fines de 1880 , momento en que se produce la crisis de las finanzas, la mecanización del campo, el subproletariado urbano; el desencanto en la difusión del progreso científico-técnico; el pensamiento de Nietzsche, Schopenhauer o el anarquismo; ${ }^{18}$ y será distinta a la española, por cuanto la burguesía catalana nunca llegó a entrar en verdadero conflicto con los intelectuales, dado que ambos sectores querían acabar con las estructuras del Antiguo régimen. En 1898, esta burguesía nacionalista catalana colabora con la intelectualidad produciéndose la cumbre de la literatura regeneracionista del Modernismo; es decir, la que formula los principios teóricos y crea los mitos nacionales de la tierra y se expresa en revistas como Catalònia. Esta línea básica que identifica catalanismo con conservadurismo (reflejada en el triunfo de la Lliga Regionalista) supone la sumisión de los intelectuales a las directrices de dicho partido o la aceptación de un dirigismo cultural que será el rasgo definidor del Noucentisme. No faltan estudios comparativos resaltando diferencias o similitudes entre la sociedad castellana y la catalana, ${ }^{19}$ poniendo en paralelo sus figuras clave: Miguel de Unamuno y Joan Maragall. ${ }^{20}$ La actitud del catalán ante la crisis del 98 es de

\footnotetext{
${ }^{14}$ Ll. Marfany [1978].

15 X. Aviñoa [1985 y 1988].

to J. Miracle [1960].

17 Señalada por J. Molas [1970:877].

${ }^{18}$ E. Valentí [1973].

${ }^{19}$ M. A. Capmany [1985:87] y A. Vilanova [1985:49].

20 J. M. Valverde [1985: 27] y B. Delgado [1988].
} 
rechazo a España por considerarla muerta y su postura, individual e independentista; aunque, ante el desastre, no niega la integración al Estado español para regenerarlo.

Las consecuencias de este enfrentamiento artista-sociedad son la marginación del intelectual, deseoso de regenerar y cambiar el mundo a través del arte o las ideas, cuya relación conflictiva con el entorno es visible en la novela Els sots feréstecs, de Raimon Casellas. En ella, es el descubrimiento de ciertas verdades lo que lleva al protagonista hacia el individualismo, el fracaso o la soledad, como en Solitud, de Víctor Català, o en las novelas Diario de un enfermo, de José Martínez Ruiz, «Azorín», y Camino de perfección, de Pío Baroja. En paralelo, el artista se refugia en la bohemia sea dorada o trágica. La primera está formada por creadores como Ramón Casas o Santiago Rusiñol que constituyen (al oponerse críticamente a la burguesía a través del arte y la literatura) la primera generación de intelectuales rebeldes a su propia clase; entendiendo el arte como actividad autónoma, privilegiada, sacerdocio en que el artista es un militante. La segunda acoge a la gente inadaptada que fracasa.

En Cataluña, la oposición no fue tanto del artista frente a la burguesía (como hizo Ramón M. del Valle Inclán), sino contra la menestralía, y ello obliga a precisar el sentido que los modernistas daban a ambos términos. ${ }^{21} \mathrm{El}$ concepto de menestral no se identifica con una clase inferior; lo mismo que burgués, para Rusiñol, tampoco significa una clase adinerada, sino aquella que no tiembla ante lo bello. Lo que los modernistas critican de la burguesía es que sólo sea "menestralía enriquecida» $\mathrm{y}$, cuando la acusan de no ser suficientemente moderna, quieren decir que no compra bastantes bienes de consumo ostentosos. Así, para ellos, el arte por el arte, no quiere decir aquel que halla la remuneración en sí mismo, sino «arte caro»; arte para el mercado que debe promoverse en Cataluña. La tensión intelectual-burguesía, nunca resuelta por el Modernisme, será la causa final de su fracaso como proceso histórico-cultural que resolverá el Noucentisme creando la figura del «intelectual novecentista».

La segunda tendencia, el esteticismo representado por Rusiñol, se halla en el extremo ideológico opuesto a Brossa y L'Avenç, con actitudes que desde el punto de vista regenerador son escapistas respecto de los problemas del momento. ${ }^{22}$ Sus seguidores adoptan las propuestas simbolistas frente a la crisis del positivismo, abandonando la apariencia en pro del principio de intensidad emocional y de participación en el símbolo. Estas actitudes simbólico-decadentes evidencian el fin de la utopía racionalista y progresista que defendía un mundo mejor, traduciéndose en el «mal del siglo» (llámese hipocondría, abulia, spleen, ennui...). A partir de 1893, dicha estética acabó por identificar lo moderno con lo decadente, fundiéndose ambas actitudes en las sucesivas fiestas modernistas hasta $1899 .{ }^{23}$

El influjo del Prerrafaelismo inglés se comprueba tanto en las traducciones de textos teóricos como en la obra artística de los creadores. ${ }^{24}$ Los tratados

\footnotetext{
${ }^{21}$ LI. Marfany [1982:16-17].

22 J. Castellanos [1988:165].

23 J. Brossa [1893].

24 M. A. Cerdà [1981].
} 
más difundidos fueron los del crítico de arte John Ruskin. Su ideal del artista, sinónimo de poeta y artesano, es representado en Cataluña por Alexandre de $\mathrm{Ri}$ quer, director artístico de la revista de artes y letras Joventut (1900-1906), inspirada en al Yellow book de Londres (desde su contenido a sus cubiertas amarillas), en la que se reflejaba el deseo de aunar poesía, dibujo y confección artesana ${ }^{25}$ Así, a la idea esteticista del arte por el arte, hay que añadir el ideal de transformar la sociedad industrial por medio de la creación. Lo que en Inglaterra fue el movimiento llamado Art and Crafts, en Cataluña se tradujo en la Escola $d^{\prime}$ arts i oficis. ${ }^{26}$ Para Ruskin, la naturaleza era estética, digna de adoración; pero también ética, actitud visible en las decoraciones que el Modernismo catalán produjo en mobiliario, joyería, interiorismo o arquitectura, bien visible en la obra de Antoni Gaudí. ${ }^{27}$

La revista finisecular que mejor ilustra esta actitud simbolista es la efímera Luz (1897), de un año de vida, iniciada por Josep M. Roviralta y el pintor Darío de Regoyos, en la que se publicó La España Negra, de Émile Verhaeren, texto traducido e ilustrado por el mismo Regoyos y que tanta influencia tendría en la corriente del regeneracionismo castellano. En 1901, y partiendo de ella como precedente, Pablo Picasso acuerda con Santiago Rusiñol un proyecto de libro que se titularía Madrid. Notas de Arte; el cual se llevó a término sólo parcialmente en la revista Arte Joven, que el mismo Picasso funda en la capital española para difundir los postulados modernistas. En ella sigue la pauta de la catalana Pèl i Ploma, de tipografía brillante muy superior a su contenido literario, y donde publican Nonell, Mir o Picasso, quien colabora con los jóvenes del 98: Azorín, Unamuno y Baroja. ${ }^{28}$

En Cataluña, la creación de revistas ${ }^{29}$ en el fin de siglo supuso mucho más que un proliferar de diversos órganos de opinión; fue el florecimiento a su alrededor tanto de intelectuales como de redes editoriales, tertulias o instituciones; lo cual nos lleva a otro punto importante del Modernismo catalán y es el de la colaboración entre pintores y escritores, que dio como resultado un renacimiento del dibujo y el grabado al servicio de la inspiración literaria, ${ }^{30}$ caso de Quatre gats (1899).

Ello nos obliga a mencionar el problema de los géneros literarios y sus límites, pese a la arbitrariedad que supone hablar de poetas, narradores o dramaturgos en el Modernisme, por cuanto sus autores poseían un sentido totalizador del arte. Uno de los gestos en dicha búsqueda de la obra total es la invención del poema en prosa modernista, ${ }^{31}$ impreso en revistas como Joventut, y que solía acompañarse de ilustraciones (de Riquer, Utrillo...) o de música (del maestro Moreno).

\footnotetext{
${ }^{25}$ E. Trenc y A. Yates [1988].

26 E. Trenc [1977].

27 A. Cirici Pellicer [1951].

28 J. Herrera [1992].

${ }^{29}$ R. Pla [1985:87].

${ }^{36}$ F. Fontbona [1985:139] y J. Marco [1983:27-28].

${ }^{31}$ M. A. Cerdà [1900].
} 
En el terreno de la poesía, el Modernisme aboga por una defensa de la verosimilitud. Ya la revista $L$ 'Avenç había acusado la falta de sinceridad de la lírica anterior, proponiendo la construcción de un nuevo lenguaje poético. Maragall es quien lleva a cabo esta operación con su elogio de lo que él llama «la palabra viva», o expresión directa del sentir, de la vivencia personal sincera, ${ }^{32}$ que Juan Ramón Jiménez adoptará en su ideario de 1920. El valor de la espontaneidad se justifica porque nace de un estado de inspiración momentáneo y su consecuencia directa es ser fragmentaria, pues capta una iluminación efímera. Por ello, la poesía es la revelación de la esencia de las formas (Antonio Machado hablará de «la palabra esencial en el tiempo»), o la presencia de lo divino en lo humano y el único camino para acceder al ideal. Maragall expuso sus opiniones literarias en obras como: Elogi de la paraula y Elogi de la poesia. ${ }^{33}$ Su idea del poeta como intérprete de la naturaleza, y de la creación literaria cual ejercicio panteísta que convierte al escritor en puente entre el mundo natural y el espiritual, es simbolista. Por lo que la palabra pasa a ser una forma de intuición con singular poder sugestivo, capaz de mover profundamente el espíritu.

La aportación de Maragall posee un doble valor: dignificar la tarea del poeta y la poesía frente a la tradición que la redujo a un modo de lucimiento. Se abandona la idea del gran poema (Víctor Hugo, Jacint Verdaguer...); la poesía como espectáculo o expresión directa de unos sentimientos; reivindicando lo fragmentario, el poema breve, la polimetría y la poesía como comunicación indirecta, sugerente y connotadora. Junto a un interés por crear un lenguaje poético eficaz y adecuado a las nuevas ideas, alternativo a la retórica anterior, su otro empeño es dotar a la poesía del valor de «catalanidad», sacralizando la lengua vernácula. Su mejor obra, Visions $i$ cants, es una recopilación del imaginario colectivo al revitalizar los mitos autóctonos (el Comte Arnau, Joan de Serrallonga, Joan Gari), elevando a universal lo sencillo y local a través de la lengua del pueblo.

Frente al espontaneismo de Maragall, los esteticistas usan un verbo retórico. La palabra como valor en sí misma, el ideal de purismo ante un mundo decadente se revela en su culto a la forma. Prefieren una imaginería geológica, mineral, en la que joyas, mármol o piedras preciosas representan la solidez que falta en su época. Sus cultivadores son los responsables de la identificación del Modernisme con cierta extravagancia del estilo. En el mundo catalán, una variante de esta opción cultista es la que se denominó «l'estil mascle» —practicado por Raimon Casellas y Víctor Català-, por oposición al afeminado de los Juegos Florales, que buscaba un efecto duro, áspero, mediante el uso de voces vulgares impropias del lenguaje literario. ${ }^{34}$

En la prosa narrativa, aunque se ha hablado de ausencia de novela modernista ${ }^{35}$ frente a la del naturalismo, los escritores inician una búsqueda de múltiples formas, cuyo resultado es la destrucción del modelo clásico de relato. Se

32 J. Fuster [1978:44].

33 J. Castellanos [1988:231-239].

34 Una buena muestra de la poesía modernista es la antología reunida por J. Castellanos [1990].

35 J. Castellanos [1983] y A. Yates [1975]. 
acusa el auge de la narración breve, o cuento sobre dramas rurales, dado el desconocimiento de cómo hacer una novela. En esta búsqueda destaca Víctor Català, pseudónimo de Catarina Albert, quien con su drama rural Solitud (1905) encuentra la fórmula de la disgregación de la unidad estructural de la novela, evidenciando la crisis del género, como Azorín, Baroja o Unamuno lo harán en la prosa castellana. Otras obras catalanas enmarcadas en el naturalismo simbolista son: Josafat, de Prudenci Bertrana (1906); y La vida y mort d' en Jordi Freginals, de Josep Pous i Pagés (1912). Josep Yxart reúne una serie de textos críticos del momento sobre la novela tanto en la literatura catalana como castellana. ${ }^{36}$

En teatro, no hay uniformidad de 1890 a 1911 hasta su crisis - coincidente con el auge del cine-que Barcelona vive en 1915, y que no llegará a Madrid hasta 1926. Mientras en la capital española se discutía la creación de un teatro libre, Adrià Gual propone su «Teatre íntim», en cuya programación se ve una clara huella del Simbolismo y la apuesta por una renovación teatral a través de autores como Ignasi Iglesias y Felip Cortiella. Como profeta del Modernisme y modelo de artista automarginado, destaca el dramaturgo Apel-les Mestres y su concepto del artista polifacético que él mismo encarna como dibujante, pintor, músico, jardinero... Su referente es Wagner, en cuya ópera confluyen varias disciplinas: literatura, música, escenografía, expresando su idea del arte total que pasará a ser una de las aspiraciones del teatro modernista (gran parte del cual no se comprende a menos que se interprete como musical a partir de composiciones de Albéniz, Granados o Morera).

Los dramaturgos catalanes pueden dividirse en dos grupos: los que defienden el esteticismo o los que abogan en su compromiso social por la renovación antes que la estética. Ambas actitudes se dan a la vez o por etapas en los mismos autores. Rusiñol ilustra bien la evolución de las relaciones entre el modernista y la sociedad: desde la iconoclastia inicial y su rechazo a la sociedad - visible en su novela L'auca del senyor Esteve, que convertirá después en pieza teatralhasta su conformismo último, al reconocer que la burguesía paga al artista y éste la necesita. Dentro del teatro catalán, también puede hablarse de dos tendencias: una conservadora, inmovilista - la católica-y otra revolucionaria, representada por la producción anarquista. El primero fue más cultivado que el segundo, definitivamente muerto a partir de la Semana trágica de 1909.

Tal vez, el problema del fin de siglo sea la falta de sinonimia terminológica y de paralelos temporales. Si en Castilla, Joaquín Costa entendía por regeneración de España ayudar a los campesinos y atender al campo; su correlato en Cataluña, Miquel dels Sants Oliver, ve en ello un problema político-regionalista que afecta al proletariado urbano que se intenta culturizar. ${ }^{37}$ Aunque ambos son reformistas y proponen una regeneración desde arriba; mientras Costa habla de un "cirujano de hierro", el catalán le otorga a una burguesía preparada la dirección de la futura sociedad. Si en España, equivocadamente y durante años, Modernismo significó un movimiento poético hispanoamericano que llegaba a la península para convivir con la mal llamada Generación del 98; en Cataluña, fue

\footnotetext{
36 J. Yxart [1991].

${ }^{37}$ Ll. Marfany [1975].
} 
una actitud-marco que nació como proyecto regenerador conteniendo una estética plural. Es decir, el Modernismo supuso un proceso de transformación de una cultura tradicional y regional en otra moderna y nacional que empezó en la ultima década del XIX para coronarse en el dirigismo cultural del Noucentisme. De hecho, cuando éste substituye al Modernisme lo hace en un intento de nombrar de forma distinta, pero equivalente, la actitud de modernidad que permanecía en lo estético e ideológico. ${ }^{38}$ Entrado el siglo $\mathrm{xx}$, la misma voluntad de diferenciación dentro de la semejanza llevó a ciertos modernistas a buscar un término menos equívoco y que tradujera sus ideales de progreso, como Futurismo. Por encima de escuelas puede verse la estética emotiva de Maragall hallando eco en el ideario del Juan Ramón Jiménez en 1920; la continuidad del rigor novecentista catalán en la generación del 27 —sobre todo en Guillén y Salinas- y su expresión en la revista Cruz y raya. Así, el triángulo Paul Valéry, Jorge Guillén y Carles Riba nos habla de una misma estética por encima de limitaciones espaciotemporales. Mejor que Modernismo, por su polisemia, sería preferible hablar de Fin de siglo literario o movimiento fin de siglo dentro del cual se entrecruzarían corrientes de diversos países europeos cuya principal característica se hallaría en la preocupación por la Patria. Estos movimientos europeos - llámese saudasismo en Portugal; «acción francesa» en Francia; risorgimento en Italia, etc.- - vienen a ser el equivalente al 98 español y al Modernismo catalán.

\section{BIBLIOGRAFÍA}

AviñoA, Xosé: La música i el Modernisme, Barcelona, Curial, 1985, pp. 265-282.

—: «La fada de Morera i Torrents: un projecte musical modernista», Actes del Col-loqui Internacional sobre el Modernisme, Barcelona, 16-18 de diciembre de 1982, Publicacions de l' Abadia de Montserrat, 1988, pp. 117-130.

Bou, ENRIC: Poesia i sistema. La revolució simbolista a Catalunya, Barcelona, Empuries, 1989.

Brossa, Jaume: Regeneracionisme i Modernisme, Barcelona, Curial/Edicions 62, 1969.

CACHO VIU, VICENT: Els modernistes i el nacionalisme cultural. Antologia, Barcelona, Ed. de la Magrana, Diputació de Barcelona, 1984.

CAPMany, M. ${ }^{a}$ Aurk̀lıa: «Noucentisme y Novecentismo», Lliçons de Literatura comparada castellana i catalana (segles $X I X-X X$ ), Barcelona, Publicacions de l'Abadia de Montserrat, 1985, pp. 87-110.

Castellanos, Jordi: El Modernisme, Selecció de textos, Barcelona, Empuries, 1988.

—: Antologia de la poesia modernista, Barcelona, Edicions 62, 1990.

CERDÀ, Mà. ÀnGELA, Els pre-rafaelites a Catalunya. Una literatura i uns símbols, Barcelona, Curial, 1981 a.

—: Mites del Modernisme a Catalunya, Barcelona, Pages, $1981 \mathrm{~b}$.

Cirici Pellicer, AleXandre: El arte modernista catalán, Barcelona, Aymà, 1951.

38 J. Castellanos [1988]. 
Delgado, Buenaventura: «Unamuno y Cataluña», en Cincuentenario de la muerte de Unamuno, Barcelona, Fundació Caixa de Pensions, 1988, pp. 153-183.

FONTBONA, FRANCESC: «Dibuix y cartellisme», en El temps del Modernisme, Publicacions de l' Abadia de Montserrat, 1985, pp. 148-161.

FUSTER, JOAN: Literatura catalana contemporània, Barcelona, Curial 1971, pp. 11-139.

Herrera, J.: «El pensamiento noventayochista y el joven Picasso», Goya, n. ${ }^{\circ} 231$, Madrid, 1992, pp. 151-160.

Marco, JoAquim: El Modernisme literari i d'altres assaigs, Barcelona, Edhasa, 1983.

MARFAnY, JoAN Lluís, Aspectes del Modernisme, Barcelona, Curial Edicions Catalanes, 1975.

-: "La cultura de la burgesia barcelonina en la fi de segle», Serra d' Or, XX, 231, (diciembre 1978), pp. 54-63.

-: «Modernisme i Noucentisme, amb algunes consideracions sobre el concepte de moviment cultural», Els Marges, n. ${ }^{\circ} 26$ (setembre 1982), pp. 31-42.

-: «Modernisme i modernitat», en Actes del col-loqui internacional sobre el Modernisme (1982), Publicacions de l'Abadia de Montserrat, Barcelona, 1988, pp. 9-24.

MiRACle, Josep: La restauració dels Jocs Florals, Barcelona, Aymà, 1960.

Molas, Joaquim y Castellet, Josep M. ${ }^{\text {: }}$ Poesia catalana del segle XX, Barcelona, Edicions 62, 1963.

Molas, Joaquim (dir.): Història de la literatura catalana. Part moderna, vol. VIII, Barcelona, Ariel, 1986.

Pla, RAmON: «L'Avenç (1891-1915): la modernització de la Renaixença», Els Marges, 4, (mayo 1975), pp. 23-38.

-: «Les revistes artístiques i literàries del Modernisme», en El temps del Modernisme, Publicacions de l'Abadia de Montserrat, 1985, pp. 87-101.

RÀFols, Josep: Modernismo y modernistas, Barcelona, Destino, 1949 (versión catalana: Modernisme i modernistes, Barcelona, Destino, 1982).

RAILLARD, EDMOND: «Santiago Rusiñol modernista: ètica i poètica, al-legoria i simbolisme», Actes del Col-loqui Internacional sobre el Modernisme (1982), Barcelona, Publicacions de l'Abadia de Montserrat, 1988, pp. 105-115.

RIQUER, MARTÍ DE, y Molas, JoAQuIM: Història de la literatura catalana, Barcelona, Serra d'Or, vol. VIII, 1970.

Trenc-Ballester, Eliseu y Yates, Alan: Alexandre de Riquer (1856-1920), The British Connection in Catalan Modernisme, The anglo-catalan society occasional publications, 1988.

VALENTí, EDUARD: El primer Modernismo literario catalán y sus fundamentos ideológicos, Barcelona, Áriel, 1973 [resumida por J.Castellanos, Els Marges, 1, 1974, pp. 103-108].

_.: Els clàssics i la literatura catalana moderna, Barcelona, Curial, 1973.

VALVERde, José M.a.: «Generación del 98 y Modernisme», Lliçons de Literatura comparada castellana i catalana (segles XIX-XX), Barcelona, Publicacions de l'Abadia de Montserrat, 1985, pp. 27-48. 
VallCoRba, JaUme: Noucentisme, Mediterraneisme i Classicisme, Barcelona, Cuaderns crema, 1994.

VILANOVA, ANTONI: «Maragall y J. R. Jiménez»: Lliçons de Literatura comparada castellana i catalana (segles XIX-XX), Barcelona, Publicacions de l'Abadia de Montserrat, 1985, pp. 49-86.

YATES, ALAN: Una generació sense novel-la, Barcelona, Edicions 62, 1975.

YXART, JOSEP: Novel-listes i narradors, Barcelona, Curial, 1991. 